\title{
Determination of Natural Rubber in GR-S-Natural Rubber Vulcanizates by Infrared Spectroscopy
}

\author{
Max Tryon, Emanuel Horowitz, and John Mandel
}

\begin{abstract}
A rapid method for the estimation of natural rubber in vulcanizates of GR-S and natural rubber by means of infrared spectroscopy is reported. Samples were carefully prepared to contain known amounts of natural and GR-S rubber; the samples were vulcanized, extracted with acetone, and dried in a vacuum oven. Specimens from each sample were pyrolyzed in a combustion furnace at $550^{\circ} \mathrm{C}$ and the liquid pyrolyzates were analyzed by infrared absorption spectroscopy. An empirical relationship was developed in which the band intensities at 11.02 and 11.25 microns were related to natural rubber content. The experimental error of the method is characterized by a standard deviation of a single determination of 0.023 , which represents approximately 3 -percent natural rubber.
\end{abstract}

\section{Introduction}

Rubber chemists have long been aware of the limitations of current methods for the quantitative determination of rubber content of vulcanizates. For natural rubber, the direct method of analysis $[1]^{1}$ involves digestion of the sample with chromic acid, distillation of the acetic acid formed during oxidation, and titration of the distillate with standardized sodium hydroxide. This method requires considerable time and a large correction factor. In addition, unreliable results are often obtained for mixtures of natural and synthetic rubber. In the indirect method [2], all the constituents other than rubber hydrocarbon are determined, and the rubber content is calculated by difference. The procedures in this method are long and tedious, and the value obtained for rubber content reflects the cumulative error involved in the separate analyses for the nonrubber constituents. Synthetic rubber, whether alone or mixed with natural rubber, is not differentiated as such, but is merely determined as rubber hydrocarbon.

Burchfield [3] reported a qualitative method of analysis for natural and synthetic rubber in which the rubber vulcanizate is pyrolyzed, and the volatile products are collected in an indicating solution. The polymer type is then identified by the change in color of the solution. A superior method for the identification of natural and synthetic rubber was reported by Harms [4], in which the rubber is pyrolyzed in a test tube with a Bunsen burner and a portion of the decomposition products is analyzed by infrared spectroscopy. Bentley and Rappaport [5] applied a modification of Harms' method to the semiquantitative determination of nitrile rubber (Buna $\mathrm{N})$ in mixtures with a phenolic resin.

The work described in this paper was undertaken in order to develop a rapid and reliable method for the quantitative estimation of natural and synthetic rubber in vulcanized rubber compounds. It was found in this work that most of the spectral absorption bands of pyrolysis products obtained from

\footnotetext{
1 Figures in brackets indicate the literature references at the end of this paper.
}

vulcanized samples of natural rubber, GR-S ${ }^{2}$, and mixtures of these two polymers, are reproducible both in the wavelength of peak absorption and in relative intensity. Hence, the pyrolyzate lends itself to quantitative analysis for the original polymer.

In agreement with Harms [4], it was observed, early in this work, that the pyrolysis products of natural rubber showed a strong, distinct absorption band at $11.25 \mu$, while the products from GR-S showed a similar strong absorption band at $11.02 \mu$. The relative intensities of these two bands varied as the relative concentrations of the two rubbers were varied, in mixtures of the two materials. As these two bands are characteristic of the two polymers in question, and are adjacent to one another, allowing simple base line corrections and ratio measurements, the possibility of using the relative intensities of these bands as a measure of the natural rubber content was investigated. No attempt was made in this work to define the structures responsible for these bands. It was noted, however, that the band at $11.02 \mu$ is also found in polybutadiene pyrolysis products. In qualitative analysis for $\mathrm{GR}-\mathrm{S}$, bands other than the $11.02 \mu$ band are necessary to distinguish the material from polybutadiene. These bands in $\mathrm{GR}-\mathrm{S}$, as noted by Harms, are found at $6.22,6.66$, and $14.34 \mu$.

\section{Method}

Six samples of natural rubber, GR-S, and mixtures of these two polymers were prepared, according to the recipe given in table 1 , using $100,80,60,40,20$, and 0 percent of natural rubber. They were vulcanized at $140^{\circ} \mathrm{C}$ for one hr. The individual samples were then separately milled and extracted with acetone for $24 \mathrm{hr}$ to remove soluble nonrubber constituents that might complicate the infrared spectra. The rubber samples were dried in a vacuum oven at $50^{\circ} \mathrm{C}$ for $2 \mathrm{hr}$ to remove the solvent, and the samples were stored in an airtight container. The milling,

${ }^{2}$ GR-S is a synthetic rubber made by copolymerizing butadiene and styrene in the approximate proportion of 77 to 23 percent by weight, respectively. The GR-S sample used in this work contained 22.9 percent bound styrene. It is estimated, from work with similar mixtures of natural rubber and polybutadiene, that variations in the styrene content of GR-S of as much as 1-percent bound styrene in the polymer will not affect the calculated natural rubber content in a mixture by more than \pm 0.3 -percent natural rubber. 
TABLE 1. Vulcanization recipe

\begin{tabular}{|l|c|}
\hline & $\begin{array}{c}\text { Parts by } \\
\text { weight }\end{array}$ \\
\cline { 1 - 2 } Total polymer & \\
NBS standard channel black & 100 \\
Zine oxide & 50 \\
Sulfur & 5 \\
Stearic acid. & 2.5 \\
Altax (benzothiazyl disulfide) & 1.5 \\
Total compound & 151.0 \\
\hline
\end{tabular}

extraction, and vacuum drying are necessary steps in both of the usual chemical procedures [1, 2].

Four 0.5-gram specimens of each of the six rubber samples were weighed in $16 \times 150-\mathrm{mm}$ test tubes. The order of test of the specimens was according to a statistical design, that is discussed below in greater detail. Each specimen was pyrolyzed in a modified combustion tube furnace, figure 1, that was maintained at $550^{\circ} \mathrm{C}$, and the liquid distillate was collected in a micro test tube. In a preliminary study, the temperature was varied between $400^{\circ}$ and $550^{\circ} \mathrm{C}$, and only a small effect on the analytical results was noted.

A portion of the pyrolyzate was placed between two sodium chloride windows, using a lead spacer $0.025 \mathrm{~mm}$ thick. The infrared spectrum was obtained for each of the pyrolyzates in the 10.0 to $12.0 \mu$ region, using a Perkin-Elmer, model 21 recording spectrophotometer with sodium chloride optics.

Typical spectra for the pyrolyzates, obtained from the six samples of vulcanized rubber, are shown in figure 2. The time required for the six separate pyrolyses and infrared analyses is of the order of one hr.

An empirical relationship was developed for the quantitative estimation of percent natural rubber. Ratios of the transmittances at 11.02 and $11.25 \mu$

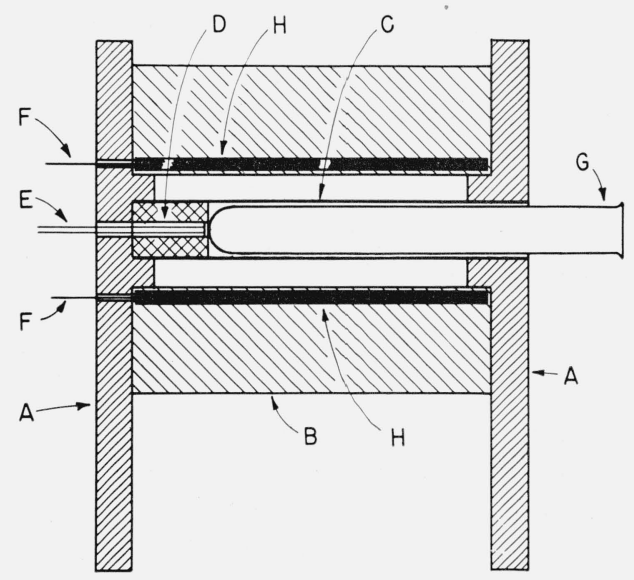

FiguRE 1. Modified combustion-train furnace for pyrolysis of polymers.

A, Transite sheet; B, furnace from combustion train; C, stainless steel tube; $\mathrm{D}$, steel plug with hole for thermocouple; $\mathrm{E}$, thermocouple; $\mathrm{F}$, heater leads; $\mathrm{G}$, test tube; $\mathrm{H}$, heater coils.

Thermocouple and heater leads connect to some type of indicator-control device such as a Wheelco Capacitrol. wavelengths, corrected for background, were used to minimize variations in cell thickness from run to run. It was found that the logarithm of this ratio was very nearly a linear function of the concentration of natural rubber in the total polymer. This is demonstrated in figure 3 . In order to avoid negative values, the ratios were multiplied by 10 , prior to taking the common logarithm of the ratio.

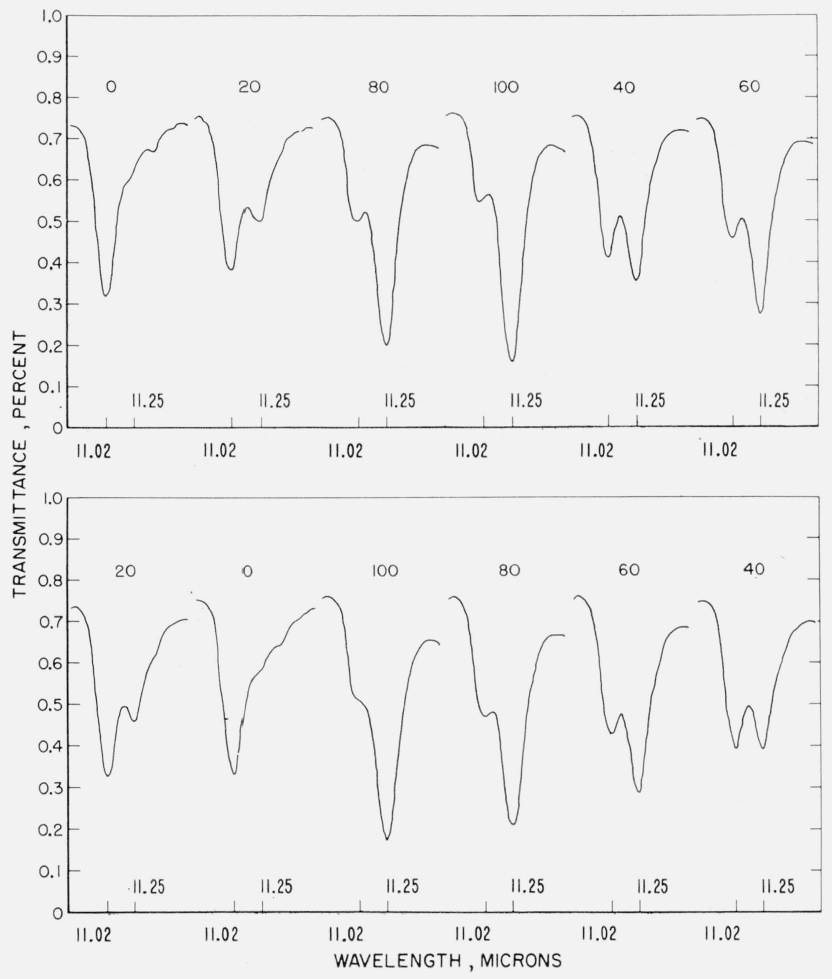

FIGURE 2. Infrared spectra of a series of pyrolysates obtained from vulcanized mixtures of $G R-S$ and natural rubber.

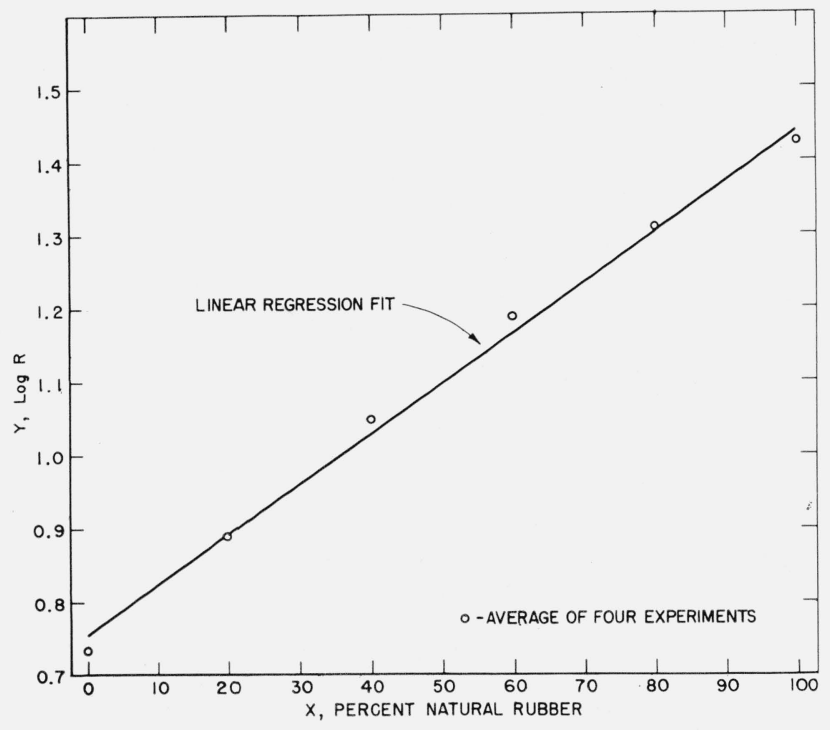

Figure 3. Calibration curve relating $\log R$ to percent natural rubber in polymer. 
The data listed in table 4 for the 24 specimens furnish the basis for the calibration curve shown in figure 3 , relating logarithm $R$ to percent natural rubber, where

$$
R=10 \frac{T_{11.02}}{T_{11.25}}
$$

and $T$ is the transmittance at the designated wavelength, corrected for background.

\section{Results and Discussion}

The type of design used in this investigation is given in table 2 [6]. The six letters in the body of the table can be identified as the six concentrations of natural rubber. By letting each row represent a complete run in which the six determinations are made in a preassigned order, associated with the columns of the table, errors resulting from instrumental instability, or similar systematic sources, can be compensated. To eliminate bias, randomizations were carried out, and the actual sequence of the determinations is shown in table 3 . The results are tabulated in table 4 , in terms of logarithms of $R$, as previously defined.

A statistical analysis of the data revealed no detectable trend of the instrument within each run, but a small amount of instability was observed from one run to another. This small additional variability does not affect the precision of the results, as each run included a complete set of concentrations of natural rubber. The standard deviation of $\log R$, reflecting the precision of a single random determination, was found to be 0.023 , which corresponds to about 3 -percent natural rubber. Thus, it can be stated with about 95 percent confidence, that a single measurement will not be in error by more than \pm 6 percent.

TaBle 2. Experimental design [6]

\begin{tabular}{|c|c|c|c|c|c|c|}
\hline & \multicolumn{7}{|c|}{ Columns } \\
\hline & \multicolumn{2}{|c|}{ Rows } & \multicolumn{2}{|c|}{} \\
\cline { 2 - 6 } & $\mathrm{l}$ & 2 & 3 & 4 & 5 & 6 \\
\hline & & & & & & \\
\hline 1 & $\mathrm{a}$ & $\mathrm{b}$ & $\mathrm{c}$ & $\mathrm{d}$ & $\mathrm{e}$ & $\mathrm{f}$ \\
2 & $\mathrm{~b}$ & $\mathrm{a}$ & $\mathrm{d}$ & $\mathrm{c}$ & $\mathrm{f}$ & $\mathrm{e}$ \\
3 & $\mathrm{e}$ & $\mathrm{f}$ & $\mathrm{a}$ & $\mathrm{b}$ & $\mathrm{c}$ & $\mathrm{d}$ \\
4 & $\mathrm{f}$ & $\mathrm{e}$ & $\mathrm{b}$ & $\mathrm{a}$ & $\mathrm{d}$ & $\mathrm{c}$ \\
\hline
\end{tabular}

TABLE 3. Order of analyses ${ }^{\text {a }}$

\begin{tabular}{|c|c|c|c|c|c|c|}
\hline \multirow{2}{*}{ Run } & \multicolumn{6}{|c|}{ Percent natural rubber } \\
\hline & 1 & 2 & 3 & 4 & 5 & 6 \\
\hline $\begin{array}{l}1 \\
2 \\
3\end{array}$ & $\begin{array}{r}60 \\
40 \\
100\end{array}$ & $\begin{array}{r}100 \\
80 \\
20\end{array}$ & $\begin{array}{r}80 \\
100 \\
0\end{array}$ & $\begin{array}{l}40 \\
60 \\
80\end{array}$ & $\begin{array}{r}20 \\
0 \\
60\end{array}$ & $\begin{array}{r}0 \\
20 \\
40\end{array}$ \\
\hline $\begin{array}{l}0 \\
4\end{array}$ & 80 & $\begin{array}{r}20 \\
0\end{array}$ & 20 & $\begin{array}{r}80 \\
100\end{array}$ & $\begin{array}{l}00 \\
40\end{array}$ & $\begin{array}{l}40 \\
60\end{array}$ \\
\hline
\end{tabular}

a The numbers in the body of the table represent the six concentrations of natural rubber, expressed as percent.
TABLE 4. Experimental values for $\log _{10} R^{\mathrm{a}}$

\begin{tabular}{|c|c|c|c|c|c|}
\hline \multicolumn{6}{|c|}{ Natural rubber-percent } \\
\hline 0 & 20 & 40 & 60 & 80 & 100 \\
\hline $\begin{array}{r}0.727 \\
.721 \\
.742 \\
.746\end{array}$ & $\begin{array}{r}0.884 \\
.880 \\
.885 \\
.890\end{array}$ & $\begin{array}{l}1.073 \\
1.050 \\
1.045 \\
1.033\end{array}$ & $\begin{array}{l}\text { 1. } 194 \\
1.184 \\
1.205 \\
1.180\end{array}$ & $\begin{array}{l}\text { 1. } 350 \\
1.291 \\
1.291 \\
1.323\end{array}$ & $\begin{array}{l}\text { 1. } 442 \\
\text { 1. } 369 \\
\text { 1. } 458 \\
\text { 1. } 459\end{array}$ \\
\hline Average 0.734 & .885 & 1.050 & 1. 191 & 1. 314 & 1. 432 \\
\hline
\end{tabular}

A calibration curve was obtained by plotting the average values, shown in table 4, corresponding to the various concentrations against the known concentrations. The data are represented satisfactorily by the following quadratic equation

$$
Y=0.730+0.00851 X-0.000015 X^{2}
$$

where $X$ is the concentration of natural rubber in percent by weight, and $Y$ is the logarithm of $R$, defined earlier. This equation fits the data within the experimental error.

If the slight curvature is neglected, the equation of the best straight line fitting the data is

$$
Y=0.755+0.00692 X .
$$

This fit is shown in figure 3.

The use of the linear equation introduces an additional error of a systematic type. This systematic error varies according to the natural rubber content. Averaged over the entire curve, it is of the order of \pm 4 percent natural rubber. Unlike experimental random error, the systematic error cannot be reduced through repeated measurements on an unknown sample. If, in the analysis of such a sample, a total uncertainty ${ }^{3}$ not exceeding \pm 6 percent natural rubber is required, triplicate determinations are necessary when the linear relationship is used, while single determinations suffice when the quadratic form is employed. A comparison of the two methods of fit is shown in table 5 .

Table 5. Comparison of calibration functions

\begin{tabular}{|c|c|c|c|}
\hline \multicolumn{3}{|c|}{$Y=\log R$} \\
\hline $\begin{array}{c}\text { Natural } \\
\text { rubber } \\
\text { concen- } \\
\text { tration } X\end{array}$ & $\begin{array}{c}\text { Observed } \\
\text { value }\end{array}$ & $\begin{array}{c}\text { Straight } \\
\text { line fit }\end{array}$ & $\begin{array}{c}\text { Quadratic } \\
\text { fit }\end{array}$ \\
\hline & & & \\
\hline 0 & 0.734 & 0.750 & 0.730 \\
20 & .885 & .891 & .894 \\
40 & 1.050 & 1.031 & 1.047 \\
60 & 1.191 & 1.172 & 1.187 \\
180 & 1.314 & 1.312 & 1.316 \\
100 & 1.432 & 1.453 & 1.432 \\
\hline
\end{tabular}

a A verage of four determinations.

3 Using a 95-percent confidence interval. 


\section{Conclusion}

The method utilizing the infrared spectra of pyrolysis products to determine natural rubber and GR-S content, respectively, in their vulcanized mixture, has been found to be more rapid than existing methods, without appreciable loss in precision. It is entirely possible that refinement of the pyrolysis procedure and the use of a sealed absorption cell in the analysis, might lead to greatly improved precision of test. It should also be possible to develop a method in which the bound styrene content in the GR-S could be estimated at the same time by utilizing the band at $14.3 \mu$ for styrene.

Acknowledgement is gratefully given to James Stewart of the Gas Chemistry Section, for his interest and assistance in obtaining the infrared data for this work.

\section{References}

[1] ASTM Book of Standards, pt. 6, D-833-46-T (American Society for Testing Materials, Philadelphia, Pa., May, 1951).

[2] Federal test method standard No. 601. Rubber sampling and testing, method 16111.

[3] H. P. Burchfield, Ind. Eng. Chem. 16, 424-25 (1944); 17, 806-10 (1945).

[4] D. L. Harms, Anal. Chem. 25, 1140 (1953).

[5] F. F. Bentley and G. Rappaport, Anal. Chem. 26, 1980-82 (1954).

[6] J. Mandel and M. Zelen, Annals of Mathematical Statistics 25, No. 4, 807 (1954) (Abstract).

Washington, June 3, 1955. 